\title{
Optimization of Process Parameters of Friction Stirs Welding of Aluminum Alloys (6061) Using Taguchi Method
}

\author{
Siva Rama Krishna $\mathbf{R}^{1^{*}}$, Pavan Kumar $\mathbf{T}^{2}$ \\ ${ }^{1}$ Assistant Professor, Nalla Narishma Reddy College of Engineering \\ ${ }^{2}$ Associate Professor, Nalla Narishma Reddy College of Engineering
}

\begin{abstract}
Friction Stir Welding (FSW) is considered to be the most significant development in metal joining technologies to join high strength aerospace aluminum alloys. In order to improve the reliability and quality of the products manufactured by FSW process input process parameters such as tool rotational speed, welding speed and axial force are to be optimized. This study deals with the optimization of process parameters for the FSW by employing the Taguchi Design of Experiment (DOE) methodology to experimentally evaluate optimum weld strength and hardness on aluminum alloy. L-9 and L-27 orthogonal arrays of Taguchi was used to analyze and determine the optimal condition, the results were put to $S / N$ analysis and Analysis of Variance (ANOVA) to find the significant welding parameters affecting the weld quality. Using ANOVA the significant factors were determined for each welding performance criteria, such as the Tensile strength. Statistical analysis of variance (ANOVA) was performed to identify the significant parameters. It is observed that Maximum Tensile strength is exhibited by FSW joints with the optimal parameters as Tool Rotational speed (A) of 1200 $\mathrm{rpm}$, Welding speed (B) of $40 \mathrm{~mm} / \mathrm{min}$ and Axial force of $4 \mathrm{KN}$.
\end{abstract}

Keywords: Taguchi Design, Friction Stirs, Welding, Aluminum, Alloys

\section{Introduction}

The major advantages of friction stir welding (FSW) in aluminum alloys, when compared to conventional fusion welds, are primarily the elimination of cracking and evaporative loss of alloying elements. This is due to the solid-state joining and a weld zone with fine worked or recrystallized grain structure generated by stirring and forging during FSW. During friction stir (FS) welding, temperatures remaining below the melting point result in a low shrinkage phenomenon and excellent mechanical properties, together with reduction of residual stress within the weld zone mechanical properties of the FSW joint are quite good and fatigue properties are practically the same as the parent metal. Generally tensile failure occurs well away from the nugget.

To date, the major application fields of FSW are marine industries( ship sections, hulls, structures), aerospace industry (fuselages, wings, fuel tanks), railway industry (high speed trains, carriages), automotive industry (chassis, wheel rims, space frames, truck bodies) motor cycle frames and other sections, such as electrical and refrigeration. Due to the combined effect of tooling, FSW produces five different microstructure zones (Fig 1). The nugget in the center of the weld where the pin has passed, A shoulder contact zone on the top surface, Thermo-mechanically affected zones (TMAZ) that are immediately on each side of the nugget, heat affected zones (HAZ) adjacent to the TMAZ that experiences a thermal cycle but not a mechanical shearing, and the unaffected parent material.

FSW produces an asymmetric micro structure in which the advancing and retreating sides experience different strain levels and thermal cycles. Material on the advancing side (rotation opposed to plate motion) experiences more shear than the retreating does. The closer the material to the tool, the higher is the deformation and temperature gradients to which it is subjected. This implies as effective deformation rate higher in the advancing side than in the retreating, resulting in different stress, flow and temperature cycles. Moreover, almost all the metal form in front of the tools is transformed to the retreating side creating a much broader flow band than that of the advancing. In addition to the grain and substructure evolution during the severe thermomechanical conditions imposed by FSW, the various thermal cycles in the different weld zones induce different precipitate distributions within each zone. This thesis presents the results of an experimental setup in which the AA6061aluminum alloy was FS Welded, using various combinations of process parameters (rotational and travel speed). Mechanical properties of the test welds were assessed by means of static tensile test. The crucial part in this work was to design an experimental setup which would fit in the available machine tool. Understanding the tool design plays a very important role in friction stir welding. The initial FSW tool designed was a simple cylindrical tool with $20 \mathrm{~mm}$ shoulder diameter, diameter and height of the pin equal to the thickness of the sheets processed i.e.,6mm.The forces generated using this tool especially during the penetration of the tool in to the work piece, were very high and caused excessive machine vibration. Then the pin of the tool is changed and two different tools tapered threaded tool and tapered hexagonal tools are used in order to reduce the initial high forces during plunging operation.

Traditionally the process parameter setting is carried out by relying heavily on the operator's experience or conservative technological data provided by the FSW equipment manufacturers, which produced inconsistent performance. The parameter settings given by the manufacturers are only applicable for the common grade steel grades. The settings 


\section{International Journal of Science and Research (IJSR) \\ ISSN (Online): 2319-7064 \\ Index Copernicus Value (2013): 6.14 | Impact Factor (2014): 5.611}

for the new materials such as Titanium alloys, Aluminum alloys, special Die steels, advanced ceramics and metal matrix composites have to be further optimized experimentally. Optimization of the FSW process often proves to be difficult task owing to many regulating variables. A Single parameter change will influence the process in a complex way. Thus the factors affecting the process have to be understood in order to determine the trends of the process variation. The selection of best combination of the process parameters for an optimal Tensile strength, involves analytical and statistical methods.

A Taguchi dynamic experiment approach is very powerful in developing a robust process design with multiple quality characteristics. Hence the main objective of this study is an attempt to apply the Taguchi dynamic method to optimize the FSW process for robustness, high efficiency, and high product dimensional accuracy. The Taguchi method, an experimental design method, has been applied for a wide range of industries. The Taguchi method adopts a set of orthogonal arrays to analyze the effect of parameters on specific quality characteristics to determine the optimal combination of parameters. These kinds of arrays use a small number of experimental runs but get maximum information. In this study, we present a method to analyze the effects of the process parameters of friction stir welding using Taguchi method.

Traditionally the process parameter setting is carried out by relying heavily on the operator's experience or conservative technological data provided by the FSW equipment manufacturers are only applicable for the common steel grades. The settings for new materials such as Titanium alloys, Aluminum alloys, Special steels have to be further optimized experimentally. Optimization of the FSW process often proves to be difficult task owing to the many regulating welding variables. A single parameter change will influence the process in a complex way.

There are several approaches to investigate the effects of different the effects of different testing parameters. The simplest method is the single parameter by single parameter approach, i.e., only one parameter is changed for a given test run. This is of course the most time consuming and costly approach as the testing parameter number is increases. To overcome this, the experimental design and dimensional analysis theory were introduced. The Taguchi methods by developing a set of standard orthogonal arrays (OA) and a methodology for the analysis of results can extract information from experiment more precisely and more efficiently than the other approaches, also less number of tests are needed even when the number of parameters being investigated is quite large. Since taguchi methods have been proved successful for many manufacturing circumstances, it is chosen in this study. The purpose of this study is to systematically investigate the effect of different process parameters and to find out the optimal condition.

\section{Literature Survey}

Adamowski and Szkodo [1] experimented, Friction Stir Welds (FSW) of aluminum alloy AW6082-T6. He summarizes the results of an experimental campaign in which the aluminum alloy AW6082-T6 was FSW Welded, using various combinations of process parameters (rotational and travel speed). Mechanical properties of the test welds were assessed by means of static tensile test, bending test. Macro and microstructure of the welds were examined by means of optical observations and Vickers hardness measurement. Raghu Babu et al [2] conducted an experimental study on the effect of welding parameters on mechanical and micro structural properties of AA 6082-T6 friction stir welded butt joints. The effect of processing parameters on mechanical and micro structural properties of aluminum alloy 6082-T6 Friction stir-welded (FSW) joints were investigated in the study. Different welded specimens were produced by employing variable rotating speeds and welding speeds. Tensile strength of the produced joints was tested at room temperature and the correlation with process parameter was assessed. Microstructures of various zones of FSW welds are presented and analyzed by means of optical microscopy and micro hardness measurements. Several studies have been conducted to investigate the properties and micro structural changes in Friction Stir Welds in the aluminum alloy 6082-T6 in function of varying process parameters. The experimental results indicated that the process parameters have a significant effect on weld macrostructure and mechanical properties of joints. Cavaliere et al [3] investigated the effect of welding parameters on mechanical and micro structural properties of AA6082 joints produced by friction stir welding. The effect of processing parameters on mechanical and micro structural properties of AA6082 joints produced by friction stir welding was analyzed. Different welded specimens were produced by employing fixed rotating speeds of 1600rpmand by varying welding speeds from 40 to 460 $\mathrm{mm} / \mathrm{min}$. The joints mechanical properties were evaluated by means of tensile tests at room temperature. Elangovan and Balasubramanian [4] worked on the Influences of tool pin profile and tool shoulder diameter on the formation of friction stir processing zone in AA6061 aluminum alloy states that Compared to the fusion welding processes that are routinely used for joining structural aluminum alloys, friction stir welding (FSW) process is an emerging solid state joining process in which the material that is being welded does not melt and recast. The welding parameters such as tool rotational speed, welding speed, axial force, etc., and tool pin profile play a major role in deciding the weld quality. The effect of tool pin profile and tool shoulder diameter on FSP zone formation in AA6061 aluminum alloy is studied. Five different tool pin profiles (straight cylindrical, tapered cylindrical, threaded cylindrical, triangular and square) with three different shoulder diameters have been used to fabricate the joints. The formation of FSP zone has been analyzed macroscopically. Tensile properties of the joints have been evaluated and correlated with the FSP zone formation. Lorrain et al [5] worked on understanding the material flow path of friction stir welding process using unthreaded tools. According to them most of studies in literature used threaded pins since most industrial applications currently use threaded pins. However, initially threaded tools may become unthreaded because of the tool wear when used for high melting point alloys or reinforced aluminum alloys. In this study, FSW experiments were performed using two different pin profiles. Both pins are unthreaded but have or do not have flat faces. 


\section{International Journal of Science and Research (IJSR) \\ ISSN (Online): 2319-7064 \\ Index Copernicus Value (2013): 6.14 | Impact Factor (2014): 5.611}

The primary goal is to analyze the flow when unthreaded pins are used to weld thin plates. Cross-sections and longitudinal sections of welds were observed with and without the use of material marker (MM) to investigate the material flow. Material flow with unthreaded pin was found to have the same features as material flow using classical threaded pins: material is deposited in the advancing side (AS) in the upper part of the weld and in the retreating side (RS) in the lower part of the weld; a rotating layer appears around the tool. However, the analysis revealed a too low vertical motion towards the bottom of the weld, attributed to the lack of threads. The product of the plunge force and the rotational speed was found to affect the size of the shoulder dominated zone. This effect is reduced using the cylindrical tapered pin with flats. Elangovan and Balasubramanian [6] studied influences of tool pin profile and welding speed on the formation of friction stir processing zone in AA2219. This process uses a non-consumable tool to generate frictional heat in the abutting surfaces. The welding parameters and tool pin profile play major roles in deciding the weld quality. In this investigation, an attempt has been made to understand the effect of welding speed and tool pin profile on FSP zone formation in AA2219 aluminum alloy. Five different tool pin profiles (straight cylindrical, tapered cylindrical, threaded cylindrical, triangular and square) have been used to fabricate the joints macroscopically. From this investigation it is found that the square pin profiled tool produces mechanically sound and metallurgical defect free welds compared to other tool pin profiles.

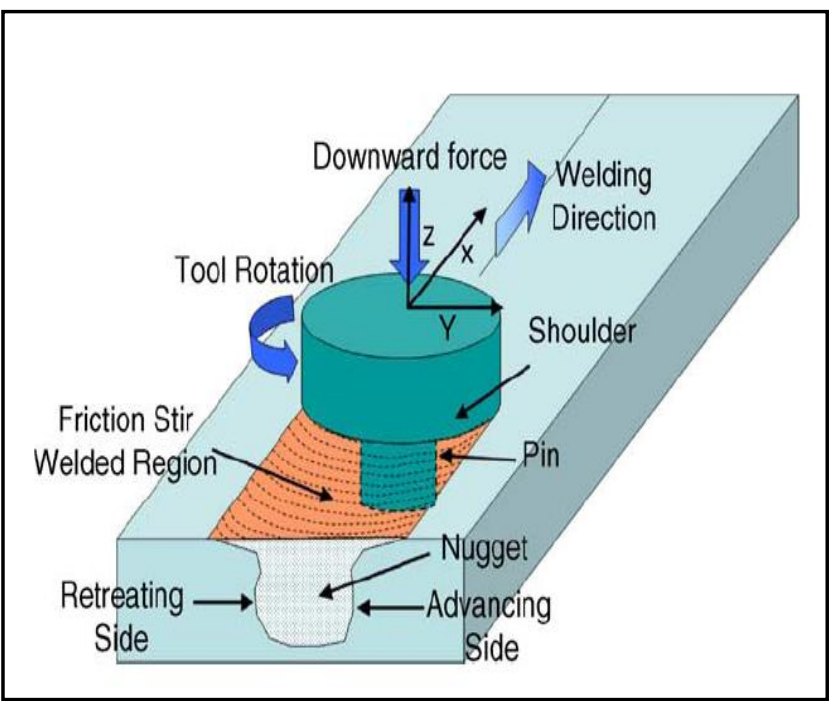

Figure 1: Schematic view of Friction stirs welding

\section{Methods / Approach}

Experimental design methods were originally developed by Fisher. However, classical experimental design methods are too complex and not easy to use. Furthermore, a large number of experiments have to be carried out when the number of process parameters increases. To solve this problem, the Taguchi method [7, 8 and 9] uses a special design of orthogonal arrays to study the entire parameter space with a small number of experiments. The experimental results are then transformed into signal-to-noise(S/N) ratio. The signal-to-noise ratio can be used to measure the quality characteristics deviating from the desired values. Usually, there are three categories of quality characteristics in the analysis of the signal-to-noise ratio, that is, the lower- thebetter, the higher-the-better, and nominal-the-better. Regardless of the category of the quality characteristic, the larger signal-to-noise ratio corresponds to the better quality characteristic. Therefore, the optimal level of the process parameters is the level with the highest signal-to-noise ratio. Furthermore, a statistical analysis of variance (ANOVA) is performed to see which process parameters are statistically significant. The optimal combination of the process parameter can then be predicted based on the above analysis. Finally, a confirmation experiment is conducted to verify the optimal process parameters obtained from the parameter design.

\section{Selection of quality characteristics}

The first step in the Taguchi method is to determine the characteristic to be optimized. The quality characteristic is a parameter whose variation has a critical effect on product quality. It is the output or the response variable to be observed. Examples are weight, cost, corrosion, target thickness, strength of a structure and electromagnetic radiation. Quality characteristic refers to the sense of desirability to the response. Depending on the objective of the experiment and how it is evaluated(what is used to measure), quality characteristic will be one of three kinds: small is better, bigger is better and nominal is better. The objective of this study was to determine the machining conditions required to achieve $\mathrm{S} / \mathrm{N}$ ratio in friction stir welding process.

\section{Selection of factors}

In Taguchi method, process parameters which influence the process are separated into two main groups: control factors and noise factors. The control factors are those design factors that can be set and maintained. Noise factors are those parameters which are either uncontrollable or are too expensive to control. Noise factors include variations in environmental operating conditions, deterioration of components with usage, and variation in response between products of same design with the same input. The levels for each control factor must be chosen at this point. The nonlinear relationship among the process parameters, if it exists, can only be revealed if more than two levels of the parameters are considered. Thus each selected parameter was analyzed at three levels. The control factors are used to select the best condition for stability in design of manufacturing process, whereas the noise factors are special variables that affect system function which are either uncontrollable or too expensive to control. The process parameters chosen for the experiment are Rotational speed $(\mathrm{N})$, Welding speed, axial pressure, these parameters were selected because they can potentially affect $\mathrm{S} / \mathrm{N}$ ratio in friction stir welding and considered to be controllable factor. The machining conditions and number of levels of the parameters are selected as follows Table 1.

\section{Selection of orthogonal array}

The optimal process parameters are determined by analyzing the characteristic data acquired by using orthogonal arrays (OA). The number of degrees needs to be computed to select an appropriate orthogonal array for the experiments. Taguchi provides many standard orthogonal arrays and corresponding linear graphs for this purpose. In our project 


\section{International Journal of Science and Research (IJSR) \\ ISSN (Online): 2319-7064 \\ Index Copernicus Value (2013): 6.14 | Impact Factor (2014): 5.611}

we are considering three factors i.e., process parameters of friction stir welding are for the three factors and three levels Taguchi proposed some standard array. Hence an $\mathrm{L}_{9} \mathrm{OA}\left(3^{3}\right)$ was selected for this study. This array specifies nine experimental runs and has three columns.

Table 1: Taguchi design for FSW optimization

\begin{tabular}{|c|l|c|c|c|}
\hline S. No. & \multicolumn{1}{|c|}{ Factor } & Level 1 & Level 2 & Level 3 \\
\hline 1 & A: Rotational speed. & 1000 & 1200 & 1400 \\
\hline 2 & B: Welding speed & 22 & 40 & 75 \\
\hline 3 & C: Axial Force & 2 & 3 & 4 \\
\hline
\end{tabular}

\section{Conduct the Experiment}

The next step is to conduct the experiment and record the results. The test run is designated by replacing the level number 1, 2, 3 of parameters A, B, C in Lg orthogonal array with the chosen parameters level values. Each row of the array represents a test run parameter setting condition. Table 2 is the test run design. Nine experimental runs were conducted as per the orthogonal array at random to avoid any systematic error creeping into the system. The $\mathrm{S} / \mathrm{N}$ ratios were recorded.

\section{Rotating speed of the tool}

According to the thermal analysis of FSW, the average frictional heat input (q) per unit area and per unit time is given by Frigard

$q=\omega 2 R 0 \pi \mu P r 2 \mathrm{dr}$.

where, $q$ is the net power intensity ( in Watts/m2), $\omega$ the angular velocity (in rad/s), $\mu$ the coefficient of friction, $\mathrm{R}$ the radius of the tool's shoulder (in meters), $\mathrm{P}$ the pressure across the interface (here assume constant). By substituting $\omega=130 \pi n$ into equal, we get

$q=230 R 0 \pi 2 \mu P n r 2 d r=145 \pi 2 \mu(R 3-r 3) \ldots \ldots$ (2) where, $\mathrm{n}$ is the rotating speed of the tool (in $\mathrm{rad} / \mathrm{min}$ ). From eqn 2, it is obvious that the rotating speed is one of the main factors affecting the frictional heat. If the rotating speed is too low, the frictional heat is not enough to induce plasticized flow, the metal in the weld cannot diffuse and recrystallized, and there are holes in the weld. Along with an increase of the rotating speed, the frictional heat increases, the plasticized layer increase from top to the underside, the holes in the weld become smaller. When the rotating speed reaches a certain number, the holes in the weld becomes tightness. But if the rotating speed is too high, the temperature of materials beneath the tool's shoulder and around the probe will excess the melt point, and the weld is no long a solid-state joint.

\section{Welding velocity}

From equation 2, we can understand that the net power intensity is constant only when the structure of the weld tool and the rotating speed are confirmed. So, when the welding velocity is too small, the frictional heat makes the temperature in the weld too high (may reach or excess the melt point), the materials will be porous, inducing fluidification crack, and the weld surface will be irregular. On the other hand, when the welding velocity is too large, the frictional heat is not enough to plasticize the materials beneath the tool' s shoulder and around the probe, the work pieces can't be welded.

\section{Axial force of tool on the work pieces}

The press force of tool on work pieces affects the contact state, whereas the contact state affects the forming of weld. When the press force is not enough, the surface metal of the weld "floats" upward and overflows the surface of work pieces, resulting in holes at the bottom of the welding. When the press force is too large, the frictional force between the tool's shoulder and the work pieces' surface increases, the tool's shoulder will cohere with the materials of work pieces and there will be flashes and burs on the weld face.

\section{Experimentation}

In this process, a cylindrical-shouldered tool with profiled threaded/unthreaded pin is rotated at a constant speed and fed at a constant traverse rate into the joint line between two pieces of plate material, which are butted together. The parts to be clamped rigidly onto a backing bar in a manner that prevents the abutting joint faces from being forced apart. The length of the pin is slightly less than the weld depth required and the tool shoulder should be in intimate contact with the work piece surface. The pines then moved against the work piece or vice-versa. Frictional heat is generated between the wear resistant welding tool shoulder and pin, and the material of the work pieces. This heat along with the heat generated by the mechanical mixing process and the adiabatic heat within the material, cause the stirred materials to soften without reaching the melting point. As the pin is moved in the direction of welding the leading face of the pin, assisted by a special pin profile, forces plasticized material to the back of the pin whilst applying a substantial forging force to consolidate the weld metal. The welding of the material is facilitated by severe plastic deformation in the solid state involving dynamic recrystallization of the base material. The welded joints will be sliced using power hacksaw and then machined to required dimensions, American Society for Testing of Materials (ASTM E8M-04) guidelines should be followed for preparing the test specimens.

The specimens of the size of $200 \mathrm{mmx} 80 \mathrm{mmx} 2 \mathrm{~mm}$ and 200mmx80mmx3mm were machined from AA6061 aluminum alloy plates. The two plates of AA6061 aluminum alloy were Friction stir welded using four different tool profiles like taper cylindrical, triangular, square and hexagonal made of high carbon high chromium steel. It comprises of $18 \mathrm{~mm}$ shoulder dia, $3 \mathrm{~mm}$ pin diameter and $1.8 \mathrm{~mm}$ pin length under the constant process parameters of $1000 \mathrm{rpm}, 14 \mathrm{~mm} / \mathrm{min}$ welding speed and $4 \mathrm{kN}$ axial force were applied in the butt configuration by using M-Tab vertical milling machine. The rotation of the tool resulted in stirring and mixing of material around the rotating pin and the linear movement of the tool moved the stirred material from the front to the back of the pin and finished the welding process. The insertion depth of the pin into the work pieces was associated with the pin height (length). The tool shoulder contacting the work piece surface depends on the insertion depth of the pin, which results in generation of welds with inner channel, surface groove, and excessive flash. These experiments were done in CNC machine 


\section{International Journal of Science and Research (IJSR) \\ ISSN (Online): 2319-7064 \\ Index Copernicus Value (2013): 6.14 | Impact Factor (2014): 5.611}

\section{Results / Discussion}

The last column in the ANOVA indicates the relative influence of the column effects (factor). The numbers in percentage (\%) are determining by taking ratio of the sum of squares of factor $\left(\mathrm{SS}_{\mathrm{F}}\right)$ to the total sum of squares $\left(\mathrm{SS}_{\mathrm{T}}\right)$. from the last column of ANOVA table significance of the factor influences can be determined by testing's for significance. A small percentage (\%) of influence to the variation of the results means that the factor tolerance can be relaxed, while the tolerances for factors that show higher percentages of influence, may have to be tightened carefully. The sum of all percentage influence always adds up to $100 \%$. The purpose of the analysis is to determine the factors and their strong effects on the welding performance. It is evident from the table factor A (Rotational Speed) is significant factor where as factor B (Welding Speed) and C (Axial force) are less significant factors for maximization of welding tensile strength. Here we got the almost same percentage contribution of the parameters in Mini tab software. Best parameters are N2 (1200), S2 (40), F3 (4). Confirmation Experiments with N1200, S40; F4 the Tensile strength achieved is 151 . These results are represented in Tables $3-7$ and Figures 2 to 4 .

Table 2: Represents Model of L-9 orthogonal array

\begin{tabular}{|c|c|c|c|}
\hline S. No & $A$ & $B$ & $C$ \\
\hline 1 & 1 & 1 & 1 \\
\hline 2 & 1 & 2 & 2 \\
\hline 3 & 1 & 3 & 3 \\
\hline 4 & 2 & 1 & 2 \\
\hline 5 & 2 & 2 & 3 \\
\hline 6 & 2 & 3 & 1 \\
\hline 7 & 3 & 1 & 3 \\
\hline 8 & 3 & 2 & 1 \\
\hline 9 & 3 & 3 & 2 \\
\hline \multicolumn{4}{|r}{}
\end{tabular}

Table 3: Represents L-9 Orthogonal array from Full Factorial Table

\begin{tabular}{|c|c|c|c|c|c|c|c|c|}
\hline \multirow[b]{2}{*}{ S. No } & \multirow{2}{*}{$\begin{array}{l}\text { Rotational } \\
\text { Speed (N) } \\
\text { (A) Rpm }\end{array}$} & \multirow{2}{*}{$\begin{array}{l}\text { Welding } \\
\text { Speed } \\
\text { (B) } \mathrm{mm} / \mathrm{min}\end{array}$} & \multirow{2}{*}{$\begin{array}{c}\text { Axial Force } \\
(K N)\end{array}$} & \multicolumn{3}{|c|}{ Tensile Strength Mpa } & \multirow[t]{2}{*}{ Average } & \multirow{2}{*}{$\begin{array}{c}S / N \text { ratio } \\
d B\end{array}$} \\
\hline & & & & Sp 1 & Sp 2 & Sp 3 & & \\
\hline 1 & 1000 & 22 & 2 & 113 & 109 & 108 & 110 & 40.82 \\
\hline 2 & 1000 & 40 & 3 & 129 & 129 & 126 & 128 & 42.14 \\
\hline 3 & 1000 & 75 & 4 & 123 & 128 & 127 & 126 & 42 \\
\hline 4 & 1200 & 22 & 3 & 125 & 126 & 124 & 125 & 41.93 \\
\hline 5 & 1200 & 40 & 4 & 153 & 149 & 151 & 151 & 43.57 \\
\hline 6 & 1200 & 75 & 2 & 123 & 123 & 126 & 124 & 41.86 \\
\hline 7 & 1400 & 22 & 3 & 113 & 112 & 108 & 111 & 40.9 \\
\hline 8 & 1400 & 40 & 4 & 114 & 113 & 110 & 112 & 40.89 \\
\hline 9 & 1400 & 75 & 2 & 114 & 112 & 116 & 114 & 41.13 \\
\hline
\end{tabular}

Now the Expected optimum condition from the Array without interactions is: A2 B2 C3

Quality control type: Bigger is better

\section{ANOVA TABLE}

Table 4: Represents the percentage of the contribution

\begin{tabular}{|l|c|c|c|c|}
\hline \multicolumn{1}{|c|}{ Factor } & $\begin{array}{c}\text { DOF } \\
\text { (f) }\end{array}$ & $\begin{array}{c}\text { Sum of } \\
\text { Squares (SS) }\end{array}$ & $\begin{array}{c}\text { Variance } \\
\text { (V) }\end{array}$ & $\begin{array}{c}\text { Percentage } \\
\text { P (\%) }\end{array}$ \\
\hline 1.Rotational Speed (A) & 2 & 3.369 & 1.6845 & 53.07 \\
\hline 2.Welding Speed (B) & 2 & 1.52 & 0.76 & 23.9 \\
\hline 3.Axial Force & 2 & 1.488 & 0.744 & 23.44 \\
\hline
\end{tabular}

Table 6: Represents percentage contribution

\begin{tabular}{|c|c|c|c|c|c|c|c|}
\hline \multirow{2}{*}{ Factor } & \multirow{2}{*}{ DOF } & \multicolumn{2}{|c|}{ AVERAGE S/N VALUES } & $\begin{array}{c}\text { Sum of } \\
\text { Squares }\end{array}$ & Mean Square & Percentage \\
\cline { 3 - 6 } & & LEVEL 1 & LEVEL 2 & LEVEL 3 & & 49.7 \\
\hline $\mathrm{N}$ & 2 & 41.66 & 42.46 & 41.02 & 659.42 & 329.71 & 26.1 \\
\hline $\mathrm{S}$ & 2 & 41.22 & 42.24 & 41.67 & 347.30 & 173.65 & 21.8 \\
\hline $\mathrm{F}$ & 2 & 41.24 & 41.74 & 42.16 & 289.4 & 144.70 & 15.5 \\
\hline ERROR & 2 & 1.44 & 1.02 & 0.93 & 31.4 & 15.57 & 100 \\
\hline TOTAL & 8 & & & & 1327.28 & & \\
\hline
\end{tabular}

Table 7: Response for Signal to Noise Ratios CONTROL FACTOR: Larger is better

\begin{tabular}{|c|c|c|c|}
\hline Level & A & B & C \\
\hline 1 & 41.66 & 41.22 & 41.24 \\
\hline 2 & 42.46 & 42.24 & 41.74 \\
\hline 3 & 41.02 & 41.67 & 42.16 \\
\hline Delta & 1.44 & 1.02 & 0.93 \\
\hline Rank & 1 & 2 & 3 \\
\hline
\end{tabular}

Table 5: Represents selection of optimum parameters and levels

\begin{tabular}{|c|c|c|}
\hline Factors & Level description & Level \\
\hline 1.Rotational Speed & 1200 & 2 \\
\hline 2.Welding Speed & 40 & 2 \\
\hline 3.Axial force & 4 & 3 \\
\hline
\end{tabular}

\section{Volume 5 Issue 3, March 2016}

MAIN EFFCT GRAPHS FOR A, B, C against $\mathrm{S} / \mathrm{N}$ ratio From the main factor effects one determines the treatments at which one should set the control factors and the signal factor to deliver robustness. One employs the verification to determine whether the "main factors only" model adequate for the optimization being attempted and it is seen that Rotational speed (A) is dominant over other factors. Main effect graphs for the following factors Rotational speed (A), 


\section{International Journal of Science and Research (IJSR) \\ ISSN (Online): 2319-7064 \\ Index Copernicus Value (2013): 6.14 | Impact Factor (2014): 5.611}

Welding speed (B), and Axial force (C) are drawn against their corresponding $\mathrm{S} / \mathrm{N}$ ratios. It is seen that both $\mathrm{A}$ and $\mathrm{B}$ kept increasing from level 1 to 2 and decreased from level 2 to 3 and the Axial force ( $\mathrm{C}$ ) increased at each level. Hence, effects of A and B are concentrated mainly at level 2 and for $\mathrm{C}$ at level 3 in order to have maximization of tensile strength.

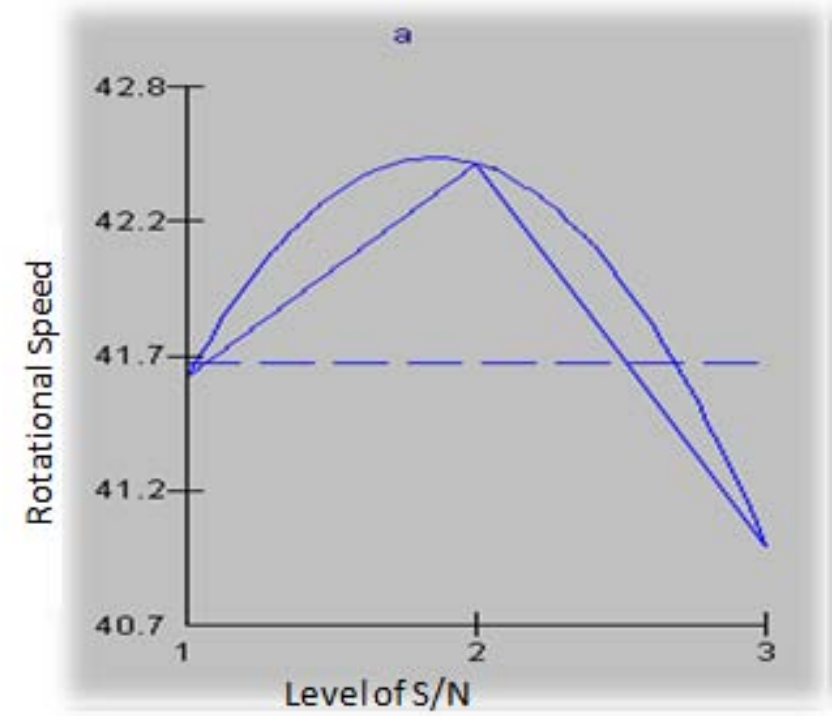

Figure 2: Rotational speed v/s S/N values

\section{Conclusions}

Tensile strength of FSW Al alloy specimen has been evaluated under different processing conditions using $3^{3}$ full factorial Experimental data applying Taguchi methodology. Primarily, L-9 array is taken into consideration and put to $\mathrm{S} / \mathrm{N}$ analysis, where the quality control type is Bigger is the Best, because we need Tensile strength to be Maximum. The reliability and quality of the products manufactured by FSW process input process parameters such as tool rotational speed, welding speed and axial force are optimized. In this process, optimization of process parameters for the FSW by employing the taguchi Design of experiments. Based on the results and observations following are the conclusions It is observed that Interaction exists between $\mathrm{A}$ and $\mathrm{C}$ its found to be significant comparatively than interaction between $\mathrm{B}$ and $\mathrm{C}, \mathrm{A}$ and $\mathrm{B}$. Including all these interactions as factors, The current L-27 array is now put to ANOVA and checked for the factor interaction severity significance and hence it is found to be negligible without altering the Optimum condition as A2 B2 C3 (AC)1. A Maximum Tensile strength is exhibited by FSW joints with Optimal Parameters: Tool Rotational speed (A):1200 rpm Welding speed (B): 40 $\mathrm{mm} / \mathrm{min}$ Axial force :4 KN.The results obtained with optimum condition are in reasonable agreement with the Experimental data Input taken.

\section{Future Scope}

In the present work experiments was made and parameters are optimized and their influence of the parameters are studied. Simulation of the FSW process can be done. Experiments can be done with dissimilar work pieces. Tools can be varied for more optimizing the parameters. Parameters are increased for more optimization. Weld defects can be studied.

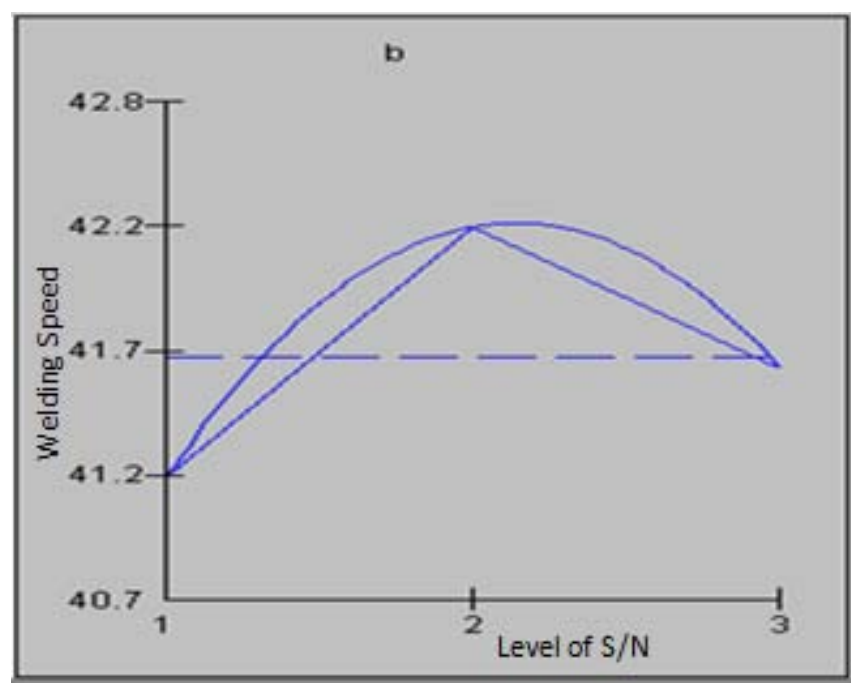

Figure 3: Welding speed v/s S/N values

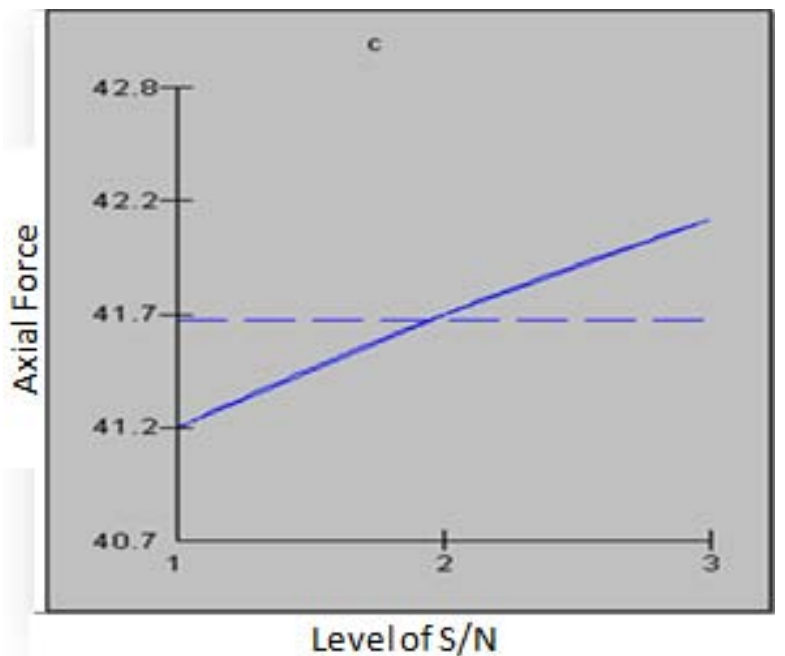

Figure 4: Axial force v/s $\mathrm{S} / \mathrm{N}$ ratio

\section{References}

[1] J. Adamowski, M. Skoda, "Friction Stir Welds (FSW) of aluminum alloy" Journal of achievements in materials and manufacturing engineering, Jan-Feb 2007, Vol. 20.

[2] G. Raghu Babu, K. G. K. Murti and G. RangaJanardhana, "An Experimental study on the effect of welding parameters on mechanical and microstructural properties of AA 6082-T6 Friction stir welded butt joints", ARPN Journal of Engineering Sciences, October 2008, Vol. 3, No. 5.

[3] P. Cavaliere, A. Squillace, F. Panella, "Effect of welding parameters on mechanical and micro structural properties of AA6082 joints produced by friction stir welding”, Journal of materials processing technology 200, PP-364-372.

[4] K. Elangovan, V. Balasubramanian, "Influences of tool pin profile and tool shoulder diameter on the formation of friction stir processing zone in AA6061 aluminum alloy", Materials \& Design, Vol. 29, No. 2, 2008, pp. 362-373. doi:10.1016/j.matdes.2007.01.030

[5] Olivier Lorrain, Veronique Favier, HamidZahrouni, Didier Lawrjaniec, "Understanding the material flow path of friction stir welding process using unthreaded 


\section{International Journal of Science and Research (IJSR) \\ ISSN (Online): 2319-7064}

Index Copernicus Value (2013): 6.14 | Impact Factor (2014): 5.611

tools", Journal of Materials Processing Technology 210 ,PP-603-609,(2010).

[6] K. Elangovan, V. Balasubramanian, “ Influences of tool pin profile and welding speed on the formation of friction stir processing zone in AA2219" Journal of materials processing technology 200 ,PP-163-175( 2008 )

[7] Paulo D J , "A note on the Determination of optimal cutting condition for Surface Finish during Turning operation using Design of Experiments", J Mater proc Tech, 2001, Vol. 116, pp- 305-308.

[8] Ross P J , Taguchi Techniques for Quality Engineering ( McGraw-Hill, New York) 1996.

[9] Theory of Taguchi methodology from Tappan .B. Bagch 